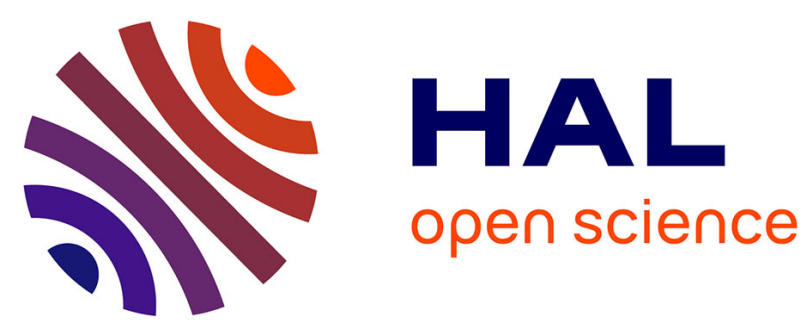

\title{
Latitudinal profile of the magnetospheric convection electric field at ionospheric altitudes from a chain of magnetic and radar data
}

Christine Mazaudier, M. Blanc, E. Nielsen, Min-Yun Zi

\section{To cite this version:}

Christine Mazaudier, M. Blanc, E. Nielsen, Min-Yun Zi. Latitudinal profile of the magnetospheric convection electric field at ionospheric altitudes from a chain of magnetic and radar data. Journal of Geophysical Research, 1984, 89 (A1), pp.375-381. 10.1029/JA089iA01p00375 . hal-00994873

\section{HAL Id: hal-00994873 \\ https://hal.science/hal-00994873}

Submitted on 22 May 2014

HAL is a multi-disciplinary open access archive for the deposit and dissemination of scientific research documents, whether they are published or not. The documents may come from teaching and research institutions in France or abroad, or from public or private research centers.
L'archive ouverte pluridisciplinaire HAL, est destinée au dépôt et à la diffusion de documents scientifiques de niveau recherche, publiés ou non, émanant des établissements d'enseignement et de recherche français ou étrangers, des laboratoires publics ou privés. 


\title{
LATITUDINAL PROFILE OF THE MAGNETOSPHERIC CONVECTION ELECTRIC FIELD AT IONOSPHERIC ALTITUDES FROM A CHAIN OF MAGNETIC AND RADAR DATA
}

\author{
C. Mazaudier and M. Blanc
}

Centre de Recherches sur la Physique de l'Environnement Centre National d'Etudes des Télécommunications

\section{E. Nielsen and Min-Yun Zi 1}

Max Planck Institut für Aeronomie

\begin{abstract}
In this paper a combination of magnetic records with coherent and incoherent radar data at auroral and middle latitudes (STARE and Saint-Santin) allows a quantitative analysis of the latitudinal profile of the convection electric field. This latitudinal profile is compared with the predictions of the semi-analytical convection model of Senior and Blanc. The auroral conductivities used in this model are deduced from comparison of the STARE electric field and the magnetic disturbance. Once this normalization is performed, a good agreement is found between the experimental and theoretical electric field profiles.
\end{abstract}

\section{Introduction}

Understanding of the electrodynamical coupling between auroral and middle latitudes can be obtained from studies of electric fields observed in the ionosphere and of magnetic disturbances recorded on the ground which are associated with the ionospheric electric fields. In the past, studies have been made separately on magnetic data [Chapman and Bartels, 1940; Akasofu and Chapman, 1961 ; Mayaud, 1965; Nishida, 1968 ; Fukushima and Kamide, 1973] on auroral electric fields, measured for instance by the STARE radar [ $\mathrm{Zi}$ and Nielsen, 1980, 1982] and on midlatitude electric fields measured by incoherent scatter radars such as the Saint-Santin radar Blanc, $1978,1980,1983 \mathrm{a}, \mathrm{b}]$. Here we examine in detail the relationship of electric fields observed along a latitudinal profile extending from mid-latitudes to the auroral zone on one experimental case (March 25, 1979).

After recalling previous experimental and theoretical works used in this study (section 2), we analyse the event of March 25, 1979. It is first argued that early in the event the electric field at mid-latitude is a result of direct penetration of magnetospheric convection only, i.e., that it is not contaminated by neutral air motion. We then use a theoretical model to fit the data (section 3 and 4). The experimental results are discussed in the last section.

\section{Previous experimental and theoretical works}

In his analysis of terrestrial magnetic field at European longitudes, Mayaud [1965] established that

\footnotetext{
${ }^{1}$ Permanently affiliated with the Geophysical Department of Peking University.
}

Copyright 1984 by the American Geophysical Union.

Paper number $3 \mathrm{~A} 1550$.

0148-0227/84/003A-1550\$02.00 during active periods the auroral $H$ component perturbation observed in the afternoon sector extended down to mid-latitudes. He interpreted this type of disturbance as an extension of the eastward auroral electrojet toward the afternoon and mid-latitude sectors and showed that this electrojet exerts more influence on mid-latitude magnetic variations than the westward one.

$\mathrm{Zi}$ and Nielsen $[1980,1982]$ studied convection at high latitudes using data from STARE (scandinavian twin auroral radar experiment). During quiet magnetic times they found the dawn convection cell to be smaller than the dusk convection cell. This implies the presence of a night to day directed conductivity gradient across the polar cap. It was found that dramatic changes take place in the electric potential distribution when the magnetic activity increases. A simple expansion of the auroral oval, which is known to take place when the kp index increases, was sufficient to explain the observations. It was concluded that a clockwise rotation of the convection pattern occur and that this rotation is associated with an enhancement of the heightintegrated conductivities in the auroral zone. The authors also concluded that the relative intensity of the region 1 and region 2 field aligned currents together with a night to day directed conductivity gradient plays an important role for the convection pattern during magnetic disturbed times. The good qualitative correspondence found between theory and experiment tends to confirm that the high-latitude electric fields are controlled by the field-aligned current ratio, the night to day gradient of the ionospheric conductivities and the conductivity enhancement within the auroral belt.

The experimental study carried out by Blanc [1978, $1983 \mathrm{a}, \mathrm{b}]$ on the electric field measured at Saint-Santin ( $\Lambda=47^{\circ}$ ) has provided the evidence of strong disturbances of the midlatitude electric field during magnetospheric substorms. These disturbances affect both the north-south and east-west electric field components. However, only the north-south component displays a systematic behavior (the east-west component of the $\vec{E} \times \vec{B}$ plasma drift). Averaging all observations for which $\mathrm{Kp}>2+$ and substracting from this average the average of all observations for which $\mathrm{Kp} \leqslant 2+$ yields an electric field disturbance (see Figure 8 of Blanc [1983 b] that is always directed northward. Its magnitude is negligible in the morning sector, of the order of $1 \mathrm{mV}^{\circ} \mathrm{m}^{-P}$ in the afternoon sector and reaches $3 \mathrm{mV}$. $\mathrm{m}^{-1}$ around $2300 \mathrm{LT}$ in the evening sector. The averaged disturbance is the result of two physical mechanisms at work simultaneously : (1) the direct penetration of the high-latitude electric field toward mid-latitudes by the closure of currents through the ionosphere and (2) the ionospheric disturbance dynamo studied by Blanc and Richmond [1980], which is the 
generation of electric fields by the dynamo effect of thermospheric neutral wind disturbances produced by the intense auroral Joule heating during magnetic storms. By a theoretical computation of the electric field distribution due to the first mechanism, Blanc $[1983 \mathrm{~b}]$ was able to reproduce the local time distribution of the observed electric field disturbance, under the assumption (based on the results of the theoretical simulations of Blanc and Richmond [1980]) the ionospheric disturbance dynamo contributes for a part to the disturbance. The contribution of the disturbance dynamo, which is directed northward and has the same amplitude at all local times, was evaluated to be about $1 \mathrm{mV}$. $\mathrm{m}^{-1}$. The major contribution was found to come from the direct penetration mechanism, which is respopsible for the diurnal amplitude observed ( $\left.3 \mathrm{mV} . \mathrm{m}^{-1}\right)$. The Saint-Santin results provide two further kinds of evidence of the efficiency of the electric field penetration mechanism. First, the time lag between the onset of any isolated substorm or convection intensification and the electric field disturbance at Saint-Santin is less than the temporal resolution ( 30 min) of the instrument, a time too short to be consistent with any mechanism operating through a modification of thermospheric circulation [Blanc and Richmond, 1980]. Second, a recent analysis by Mazaudier [1983] of simultaneous results of electric current and neutral winds in the dynamo region for the same type of events (isolated substorms or magnetic storm onsets) does not show evidence of the disturbance dynamo mechanism at the onset of the electric field disturbance, the neutral wind remaining undisturbed during the first few hours of a magnetic disturbance. The March 25, 1979, event presented here is one of these simple cases in which the electric field variation at mid-latitudes can be unambiguously attributed to the penetration of magnetospheric convection. We can, therefore, use this case as a quantitative test of convection theory. The general framework of this theory was developed analytically by Vasyliunas [1972] and Pellat and Laval [1972]. However, all analytical descriptions (including Southwood [1977] ) have used a uniform conductivity distribution. This assumption is too far from reality to allow any quantitative comparison to be made with observations of the electric field penetration at middle latitudes. At the other end of the scale of complexity, the fully numerical model developed by the Rice University group [Harel et al., $1981]$ is indeed extremely valuable for an accurate comparison with a particular substorm event. But it cannot be used directly for comparison with the event of interest here, which was not specifically simulated by this model.

Recently Senior and Blanc [1983] developed a semianalytical linear time dependent model of convection, which includes a more realistic space distribution of conductivities. While it is much more realistic than the previous analytical calculations, this model keeps the simplicity (and also indeed the limitations) of its linearity and has freely adjustable values of the high latitude conductivities. The conductivity in the auroral zone is simulated with two uniform conductivity rings : The auroral zone from colatitudes $\Theta_{o}$ to $\Theta_{2}$ and a subauroral zone from $\Theta_{2}$ to $\Theta_{1}$. For greater than $\Theta_{1}$ (middle and low latitudes) the integrated Pedersen conductivity varies during the daytime as

$$
\Sigma_{P}=\Sigma_{P}^{o} \cos x \frac{B_{o}}{B}
$$

where $X$ is the solar zenith angle, $\mathrm{B}$ is the local value of the magnetic field, $B_{p}$ and $\Sigma_{P}^{o}$ are the values of the equatorial magnetic field and conductivity at midday. (This expression is based upon a study by Senior [1980] of the ionospheric conductivities measured at SaintSantin (see also Senior et al [1981]). It was found to give a good representation of the observed local time dependence of ionospheric conductivites at middle latitudes. During the night, the conductivities are small and uniform in local time :

$$
\Sigma_{P}=\frac{\sum_{P}^{o}}{30} \frac{B_{o}}{B}
$$

the subsolar Pedersen conductance has been taken as 29 Mho and a smooth transition, between the day and night values, modeled as a parabolic function of $X$, is imposed on the dawn and dusk sectors over $20^{\circ}$ of the parameter, finally the Hall and Pedersen conductivities ratio is taken as 1.7 and a dipole magnetic field with an equatorial value of $0.28 \times 10^{\mathrm{T}} \mathrm{T}$ is used.

The inner boundary of the equatorial ring current is assumed to map down on the circle of colatitude $\theta_{1}$, which represents the equatorial boundary of the auroral zone. The model yields self consistent variations of this inner boundary in the magnetospheric equatorial plane and of the LT distribution of Birkeland currents generated along this boundary. The colatitudes $\Theta_{0}$ and $\Theta_{2}$ and conductivities in each zone are free parameters of the model, and can be adjusted to fit the observations.

Here we study the latitudinal profile of the ionospheric electric field near the onset of a disturbance during the event of March 25, 1979. After outlining the morphology of the event, on the basis of STARE and Saint-Santin data and data of a latitudinal chain of magnetometers extending from STARE to Saint-Santin latitudes, the latitudinal profile of the disturbed electric field at three times during the event will be established. The comparison between the STARE data and the local magnetometer is used to estimate the auroral conductivity. Then a quantitative comparison with the theoretical latitudinal electric field profile deduced from the Senior and Blanc model will be made.

\section{Observations on March 25, 1979}

March 25, 1979 is illustrated in Figure 1, which shows from top to bottom variations of (1) the $H$ magnetic field component at Troms $\phi(2)$ the auroral north- south electric field given by the STARE radar, (3) the Saint-Santin north-south electric field disturbance variation $\Delta \overrightarrow{\mathrm{E}}$ obtained by substracting to the observed $\vec{E}$, the quiet-day regular field model $\langle\overrightarrow{\mathrm{E}}>$ of Blanc and Amayenc 1979 .

This case is typical of the extension towards afternoon of an eastward electrojet flow. The upper curve indicates the Harang discontinuity at about 2030 UT. This can also be recognized on the STARE electric field observations (middle diagram). From 0400 to 1000 $\mathrm{UT}$, the $\mathrm{H}$ component at Troms $\phi$ was close to the baseline, STARE observed no echo, and Saint-Santin observed no disturbance. From 1000 to 1300 UT a slight northward increase of the $\mathrm{H}$ component was associated with a northward electric field disturbance at Saint-Santin, while STARE detected signals only after 1300 UT. This was due to the STARE sensitivity threshold of $15 \mathrm{mV} \mathrm{m}-1$. We notice that northward and southward auroral electric fields appear simultaneously with northward or southward $\mathrm{H}$ component deviations. The same relationship exists at Saint-Santin between 


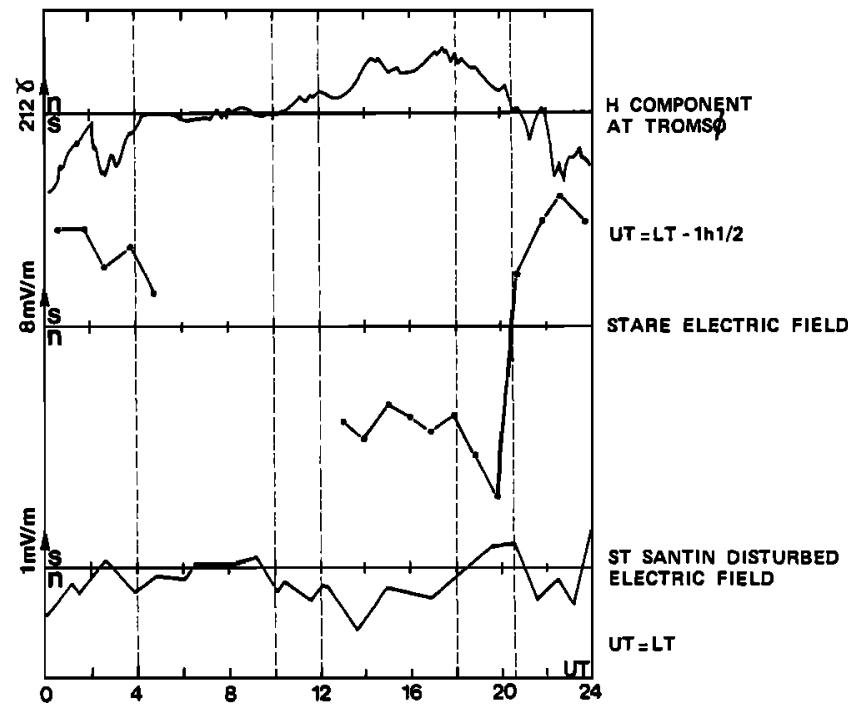

Fig. 1. Variations on March 25, 1979 of the $H$ component of the terrestrial magnetic field measured at Troms $\phi$, the auroral northward electric field measured by the STARE coherent radar and the mid-latitude northward electric field observed above Saint-Santin (incoherent scatter radar). During the afternoon (around 1300 UT) the eastward electrojet increases. The auroral and mid-latitude northward electric fields (STARE and Saint-Santin) both reveal an intensification associated with the enhancement of the eastward electrojet.

the $\mathrm{H}$ component and the disturbed electric field but only during daytime from 0600 to 1800 UT. We are interested in the daytime period especially between 1300 and 1430 UT when the auroral currents were increasing and when the electric field estimated from the STARE system is available. The magnetic data which provide spatial coverage between the STARE and Saint-Santin fields of view are presented in Figure 2 in which the left side shows the $A U$ and $A L$ indices and the $\mathrm{H}$ component time variations for eight stations of decreasing magnetic latitudes downwards.

March 25,1979 , is a magnetically disturbed day $\left(\Sigma \mathrm{km}=24^{+}\right)$. The AU and AL indices (Figure 2, upper curve) show various disturbances. Around 1300 UT, time underlined by an arrow, the auroral activity increases. North of the $54^{\circ}$ north latitude (from Leirvogur down to Nurmijarvi) we observe near 1000 UT a positive increase of the $\mathrm{H}$ component, which grows up rapidly from 1300 to 1430 UT. This positive increase follows a period of almost no change of the $H$ component (whose duration varies with latitude). As we are interested in relative magnetic changes we can use this period as zero level reference. South of the $54^{\circ}$ north latitude, the $\mathrm{H}$ variation presents a minimum near $1000 \mathrm{UT}$, which again defines a reference level for the perturbation. A moderate increase of the $\mathrm{H}$ component already occurs near 1200 UT. As the Dst equatorial index variation only reaches 2 gammas during the period 1300 to $1430 \mathrm{UT}$, we have neglected it and concluded Mazaudier, 1983 that ionospheric currents produce the major part of the magnetic perturbation. Figure $2 b$ gives the $\mathrm{H}$ perturbation function of magnetic latitude for the three times 1300, 1330 and 1400 UT. No disturbance can be found on the $\mathrm{D}$ component. The fact that the Leirvogur observation is different from the Troms $\phi$ and Abisko ones can probably be explained by a longitude effect. In this study as a first approximation we have not taken into account the difference of local time for the stations of our chain.

The $\Delta \mathrm{H}$ perturbation is related to the northward ionospheric electric field (Ex) by

$$
\Delta H \simeq J_{Y} \simeq-\Sigma_{H} E_{X}
$$

where Jy is the height-integrated eastward ionospheric
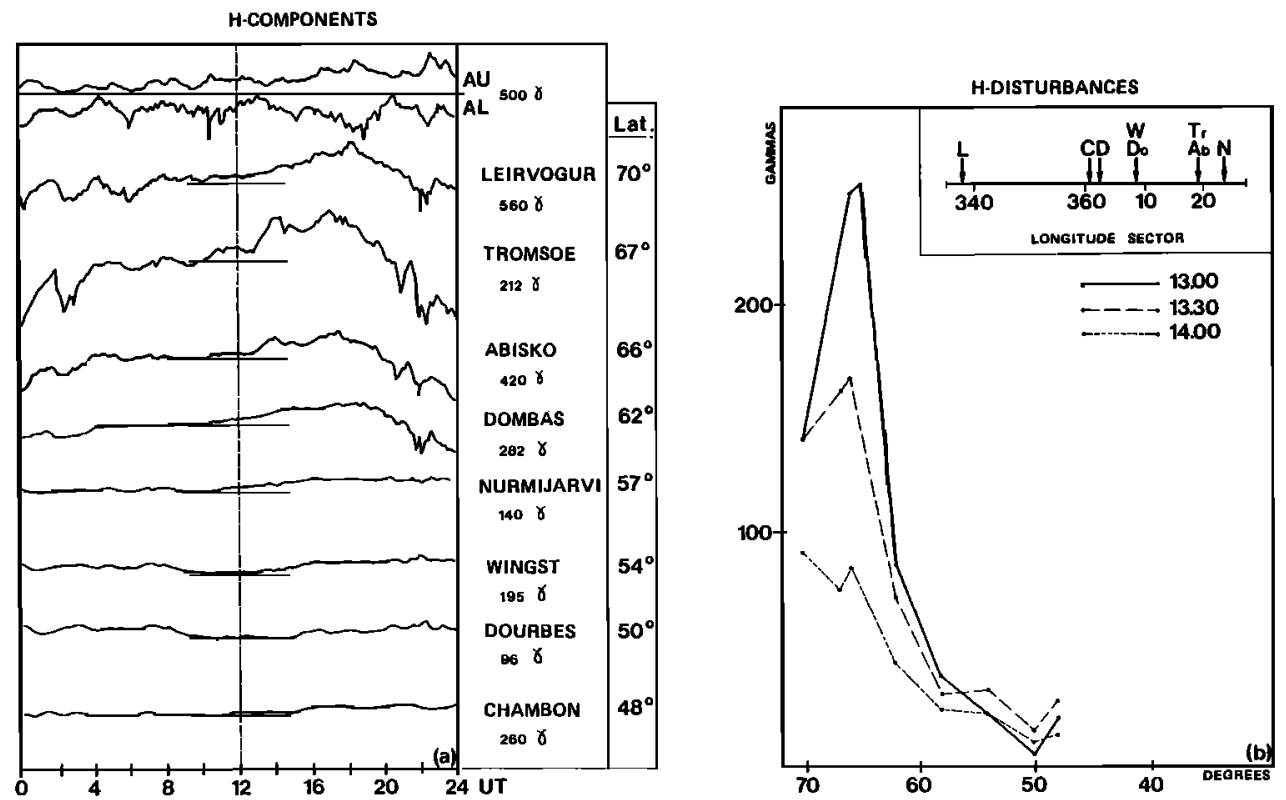

Fig. 2. This figure is composed of two panels. The left panel presents the AU and AL indexes and the $\mathrm{H}$ component of the terrestrial magnetic field for different geomagnetic latitudes. The right panel shows the latitudinal variation of the northward $\mathrm{H}$ component disturbances on March 25 , 1979 at different times (1300, 1330, 1400 UT). 
TABLE 1. The Hall Conductivities for the Three Latitude Zones: Auroral, Subauroral, and Mid-latitudes

\begin{tabular}{clcc}
\hline Latitudes & $1300 \mathrm{UT}$ & $1330 \mathrm{UT}$ & $1400 \mathrm{UT}$ \\
$72^{\circ} \leqslant \Theta \leqslant 67^{\circ}$ & $\Sigma_{\mathrm{H}}=5 \mathrm{mho}$ & $\Sigma_{\mathrm{H}}=10 \mathrm{mho}$ & $\Sigma_{\mathrm{H}}=12 \mathrm{mho}$ \\
$67^{\circ} \leqslant \Theta \leqslant 64^{\circ}$ & $\Sigma_{\mathrm{H}}=5 \mathrm{mho}$ & $\Sigma_{\mathrm{H}}=5 \mathrm{mho} \quad \Sigma_{\mathrm{H}}=5 \mathrm{mho}$ \\
$\Theta \leqslant 64^{\circ}$ & $\Sigma_{\mathrm{H}}=\Sigma_{\mathrm{H}}^{\cos \chi \mathrm{Bo} / \mathrm{B}}$ & $\Sigma_{\mathrm{H}}=\left(\Sigma_{\mathrm{H}}^{o} / 30\right) \mathrm{Bo} / \mathrm{B}$ \\
nightime
\end{tabular}

current and $\Sigma_{H}$ is the height-integrated Hall conductivity.

Expression (2) is derived from the Chapman and Bartels relation $(\Delta B \simeq 2 \pi / 10 \mathrm{f} . \mathrm{J})$ and from the Ohm's law $(\vec{J}=\overline{\bar{\sigma}}, \overrightarrow{\mathrm{E}})$ following the work of Mazaudier 1983 . In expression (2) the second term of the Ohm's law $\Sigma_{P} E_{Y}$ has been neglected. This leads to an error of approximately $25 \%$ on the evaluation of the northward electric field, since the ratios $E_{X} / E_{\text {and }}$ and $\Sigma_{H} / \Sigma_{P}$ measured at Saint-Santin are of the order of 2. Another way of estimating this error would be to use the absence of disturbance on the $\mathrm{D}$ component. If $\mathrm{D}$ were due only to the north-south ionospheric current $J_{x}$, the equation

$$
J_{\mathrm{X}}=\Sigma_{\mathrm{p}} E_{\mathrm{X}}+\Sigma_{H} E_{\mathrm{Y}}=0
$$

would lead combined with (3), to $\Sigma_{P} E_{Y} \mid \Sigma_{H} E_{X}=40 \%$. However, the $D$ component may be strongly affected by field-aligned currents, and we prefer the previous estimate based on direct ionospheric measurements. In any case the order of magnitude of the estimated error is not considerably different.

By using an EUV dependent conductivity model equation (1) we have deduced from the $H$ variation three profiles of the ionospheric northward electric field assuming in a first step that the particle precipitation is negligible in the auroral zone. The comparison of radar and magnetic data at Saint-Santin is used to evaluate the constant $\Sigma^{o}$ of expression (1).

In Figure 3 the three diagrams represent for the three times considered the electric field deduced from magnetic data (dot dashed line), from STARE (full line) and Saint-Santin (one point). At 1330 UT and 1400 UT, the STARE measured electric fields shown in diagrams $3 \mathrm{~b}$ and $3 \mathrm{c}$ are half the values of the ones deduced above from magnetic data. At Troms $b$ the Hall conductivities that would reconcile the magnetic observations with those of STARE are 10 and 12 mhos for 1330 and 1400 UT, respectively; i.e., twice larger than those produced by the solar flux only ( 5 mhos).

\section{Comparison with theory}

Using the empirical values of auroral conductivities found in the previous section and listed in Table 1, we have the electric field latitude profiles, by using the model of Senior and Blanc [1983].

The height integrated conductivity ratios $\Sigma_{H} / \Sigma_{P}$ for these three zones were chosen as, 2, 1.6, and 1.6, in the auroral, subauroral, and middle latitude zones, respectively. The time variation of the model, as in Vasyliunas [1972], is produced by the motions of the ring current inner edge. The initial electric field is assumed to be zero everywhere. At an initial time $t=0$, a dawn to dusk potential is applied at the polar boundary of the auroral zone, and it is assumed constant in time. In Figures 3a, 3b, and $3 c$ the broken curves show the theoretical electric field profiles for $t$ $=0$, i.e., before the ring current response to the applied field has been able to partly decouple the middle latitudes from high-latitude convection. From 1300 to 1430 UT auroral currents are consistently increasing and the period could be considered as permanently disturbed. The model results for $t=0$ are, therefore, the relevant ones to compare with our data from 1300 to 1430 UT. As an illustration, Figure 4 reproduces the initial time electrostatic distribution displayed in Figure 14 of Senior and Blanc. In this plot, all values of the potential are normalized to its maximum, reached at dawn on the polar cap/ auroral zone boundary. The dawn to dusk potential drop, a free parameter of the model, has been taken as $66 \mathrm{kV}$ in order to fit optimally the STARE results. Once this fit is achieved, our model links satisfactorily together the STARE and Saint-Santin data.

The value of $66 \mathrm{kV}$ is probably somewhat low, since the value of the north-south component $B$ of the interplanetary magnetic field is of the order $5 \mathrm{ZT}$ during the events. The linear formula of Reiff et al. [1981] based on the direct measurement of the dawn to dusk potential drop by polar orbiting satellites, would give a value slightly above $100 \mathrm{kV}$. However, this discrepancy may be a consequence of the geometry of the polar boundary of the auroral zone, which is displaced toward midnight, whereas in the Senior and Blanc model it is represented by a circle centered on the magnetic pole. This must result in an underestimate of the polar cap potential drop, since the STARE field of view is farther from the real polar cap than from the model one.

To give an idea of the agreements and discrepancies found for the smaller east-west component Ey of the convection electric field, Table 2 presents the ratio of $E$ to $E$ for the three times studied and for the latitudes of STARE and Saint-Santin measurements. One sees that the simulation underestimates this ratio at high latitudes but overestimates it at the latitude of Saint-Santin. The high values of $E_{X} / E_{Y}$ predicted by the model at Saint-Santin actually reflect the fact that $E_{Y}$ is small on the dayside and furthermore reverses its direction close to $1400 \mathrm{LT}$. Overall, it is clear that the $E_{y}$ component is not very well reproduced by the model.

\section{Conclusion}

In this paper the combination of magnetic records with coherent and incoherent radar data obtained at auroral and middle latitudes allows a quantitative 

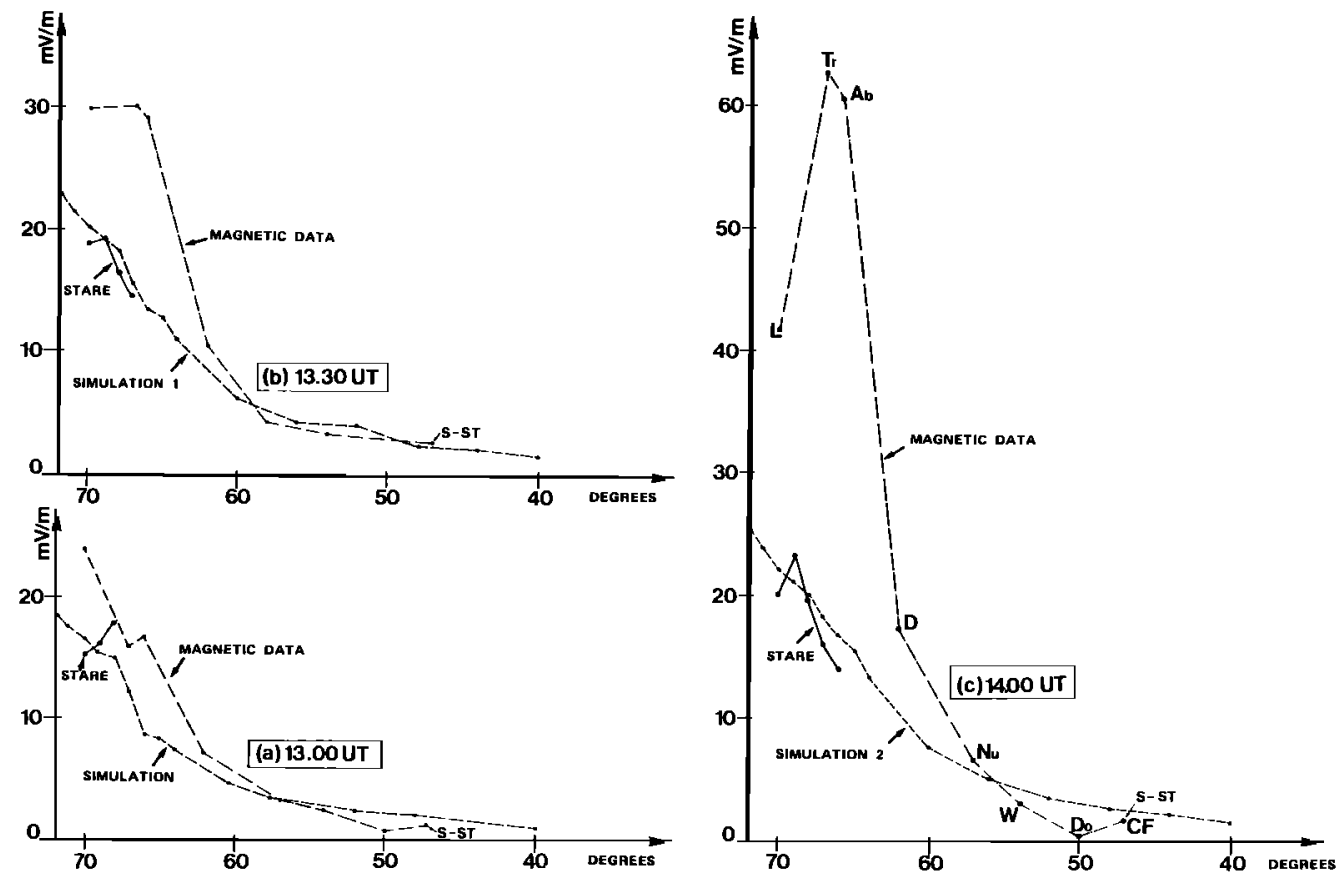

Fig. 3. On each panel are presented the STARE (full line) and Saint-Santin northward electric field, the latitudinal profiles of the electric field deduced from magnetic data (dot-dashed line) and from the convection model of Senior (dotted line). The two left-hand side panels are for 1300 UT and $1330 \mathrm{UT}$, the right-hand side is for $1400 \mathrm{UT}$. The auroral conductivites used in this model are deduced from comparison of the STARE electric field and the magnetic disturbance. The model links satisfactory together the STARE and Saint-Santin data.

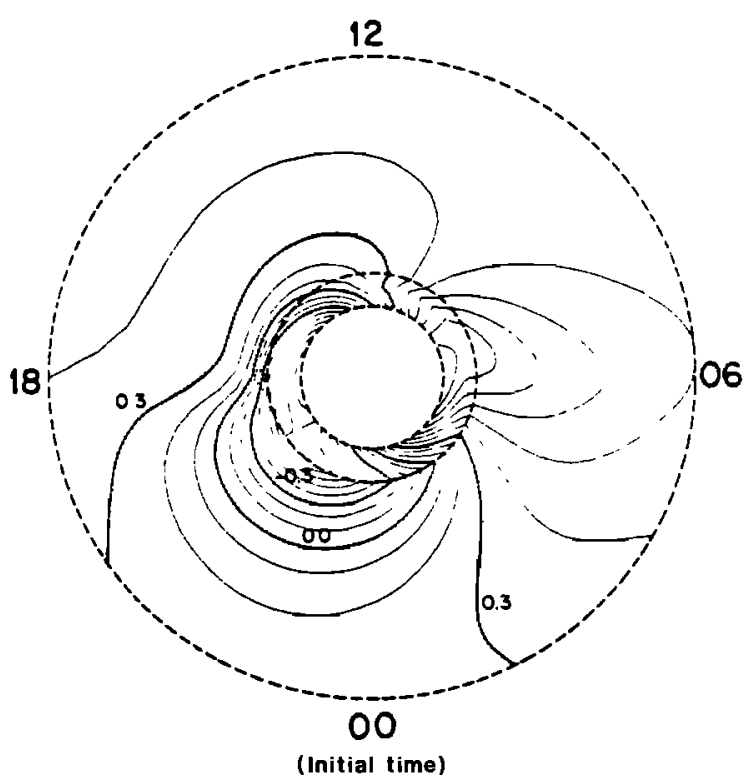

Fig. 4. Electrostatic potential distribution over one ionospheric hemisphere produced at the initial time by the convection model of Senior and Blanc [1983]. The three dashed circles represent, from the center outward, the poleward boundary of the auroral zone, the equatorward boundary of the subauroral zone, and the boundary of the equatorial electrojet region (located at $10^{\circ}$ latitude). This plot was made for Pedersen conductivities of 5 and 2.5 mhos, and Hall to Pedersen conductivity ratio of 2 and 1.6, in the auroral and subauroral zones, respectively. analysis of the latitudinal profile of the convection electric field.

The electric field profile was deduced from the magnetic $\mathrm{H}$ component variation by using a model of the mid-latitude conductivities function of the solar zenith angle. At auroral latitudes this method may be inadequate if electron precipitation is present, because it enhances ionospheric conductivities above the level due solely to solar photoionization. But the ratio of the measured $\mathrm{H}$ deviation to the electric field measured by STARE can then be used to infer the real value of the auroral zone conductivities.

Knowing this value, it was possible to compare the meridional electric field profile deduced from our chain of measurements with the predictions of the convection electric field model of Senior and Blanc [1983]. This semianalytical linear and time-dependent model includes a realistic distribution of middle latitude ionospheric conductivities, and a ring of uniform conductivities in the auroral zone. Once the auroral conductivity values deduced from the data were assigned to this ring and the other free parameter of the model, the dawn to dusk electrostatic potential drop across the polar cap, was adjusted to a value of 66 $k v$, a good agreement between the experimental and theoretical meridional electric field profiles was obtained. This result supports the initial hypothesis that the mid-latitude electric field disturbance was due entirely to a direct penetration of magnetospheric convection.

Simple cases such as the one reported are not the only ones for which magnetospheric convection extends directly to mid-latitudes. But their simplicity allows a rather accurate confrontation between observations and linear theories, and, therefore, makes them a useful test of convection models. No definite conclusion can indeed be drawn from a single example, and more 
TABLE 2. Electric Field Deduced from Theoretical Simulations and Measured by the STARE and Saint-Santin Radar

\begin{tabular}{|c|c|c|c|c|c|c|c|c|c|c|c|}
\hline \multirow[b]{2}{*}{ Time, UT } & \multicolumn{6}{|c|}{$\begin{array}{l}\text { Theoretical Simulations, } E_{x} / E_{y} \\
\text { Latitude }\end{array}$} & \multicolumn{4}{|c|}{$\begin{array}{l}\text { STARE, } E_{x} / E_{y} \\
\text { Latitude }\end{array}$} & \multirow{2}{*}{$\frac{\begin{array}{c}\text { Saint-Santin } \\
\text { Latitude }\end{array} \mathrm{E}_{\mathrm{x}} / \mathrm{E}_{\mathrm{y}}}{48^{\circ}}$} \\
\hline & $70^{\circ}$ & $69^{\circ}$ & $68^{\circ}$ & $67^{\circ}$ & $48^{\circ}$ & $70^{\circ}$ & $69^{\circ}$ & $68^{\circ}$ & $67^{\circ}$ & $66^{\circ}$ & \\
\hline 1300 & 1.3 & 1.4 & 1.6 & 1.7 & 7.2 & 10 & 3.7 & - & - & - & 19 \\
\hline 1330 & 1.7 & 1.7 & 1.9 & 1.7 & 11.7 & 12 & 10 & 3.5 & 2.1 & - & 2.5 \\
\hline 1400 & 1.9 & 2 & 2 & 2 & 30 & 14 & 34 & 5.8 & 4 & 2.5 & 1.7 \\
\hline
\end{tabular}

systematic comparisons are to be made, if possible, for a sample of measurements covering the different sectors of local time.

Acknowledgement. The authors are indebted to A. Brekke for helpful comments.

The Editor thanks the two referees for their assistance in evaluating this paper.

\section{References}

Akasofu, S.-I., and S. Chapman, A neutral line discharge theory of the aurora polaris, Phil. Trans. $\underline{\text { R. }}$ Soc. London Ser. A., 253, 359-406, 1961.

Blanc, M., Mid-latitude convection electric fields and their relation to ring current development, Geophys. Res. Lett., S, 203-206, 1978.

Blanc, M., P. Amayenc, Seasonal variations of the ionospheric $E \times$ B drifts. J. Geophys. Res., 84, 2691, 1979.

Blanc, M., Le champ électrique ionosphérique de moyenne latitude et les dynamos de la haute atmosphère: Etude expérimentale par diffusion incohérente, et contribution à une interprétation théorique, Thèse de doctorat d'Etat, Université Pierre et Marie Curie, Paris, 1980.

Blanc, M., and A. D. Richmond, The ionospheric disturbance dynamo, J. Geophys. Res., 85, 1669-1686, 1980.

Blanc, M., Magnetospheric convection effects at mid-latitudes, 1, Saint-Santin observation, J. Geophys. Res., 88, 211-223, 1983a.

Blanc, $\vec{M}$., Magnetospheric convection effects at mid-latitudes, 3, Theoretical derivation of the disturbance convection pattern in the plasmasphere, J. Geophys. Res., 88, 235-251, 1983b.

Chapman, S., and J. Bartels, Geomagnetism, Oxford University Press, London, 1940.

Fukushima, N., and Y. Kamide, Partial ring current models for worldwide geomagnetic disturbances, Rev. Geophys. Space Phys,. 11, 795, 1973.

Harel, M., R. A. Wolf, P. H. Reiff, R. W. Spiro, W. J. Burke, F. J. Rich, and M. Smiddy, Quantitative simulation of magnetospheric substorm, 1, Model logic and overview, J. Geophys. Res., 82, 2217, 1981 .

Mazaudier, C., Contribution à l'étude des courants électriques, des champs électriques et des vents neutres ionosphériques de moyennes latitudes, variation régulière et variations perturbées: Etude de cas à partir des observations du sondeur à diffusion incohérente de Saint-Santin en relation avec les observations du champ géomagnétique terrestre (vol. 2) Thèse de doctorat d'Etat, Université Pierre et Marie Curie, Paris 6, 1983.

Mayaud, P. N., A propos de la contamination de la variation journalière $\mathrm{Sq}$ du champ magnétique par la variation journalière $S D$ et d'un type spécial de perturbations contribuant au SD d'été, Ann. Géophys. $21,219,1965$.

Nishida, A., Geomagnetic Dp2 fluctuations and associated magnetospheric phenomena, J. Geophys. Res., 83, 1795, 1968.

Pellat, R., and G. Laval, Remarks on the steady and time dependent mathematical, convection models, in Critical Problems of Magnetospheric Physics, edited by E.R. Diyer, Inter-Union commission on Solar-Terrestrial Physics, Washington, D. C., 1972.

Reiff, P. H., R. W. Spiro, and T. W. Hill, Dependence of polar cap potential drop on interplanetary parameters, J. Geophys. Res., 86, 7639, 1981.

Senior, C., and M. Blanc, On the control of magnetospheric convection by the spatial distribution of ionospheric conductivities. In press. 1983. J. Geophys. Res.

Senior, C., les conductivités ionosphériques et leur rôle dans la convection magnetosphérique : une étude expérimentale et théorique, thèse de 3ème cycle, Université Paris, 1980.

Senior, C., P. Bauer, C. Taî̉, and M. Petit, le rôle de l'oxyde d'azote dans la distribution de densité électronique de la région $\mathrm{E}$ en fonction de l'angle zénithal solaire C. R. Acad. Sci. Paris, 292, Série II, $1195,1981$.

Southwood, D. J., The role of hot plasma in magnetospheric convection, $]$. Geophys. Res., 82 , 5512 , 1977.

Vasyliunas, V. M., The interrelationship of magnetospheric processes, in "Earth's Magnetospheric processes", Edited by B. M. McCormac, D. Reidel, Hingham, Mass., 1972.

$\mathrm{Zi}$, M., and E. Nielsen, Spatial variations of ionospheric electric fields at high latitudes on magnetic quiet days, edited by C. S. Deehr and J. A. Holtet, Exploration of the Polar Upper atmosphere, pp. 293-304, Hingham, Mass., 1980.

$\mathrm{Zi}$, M., and E. Nielsen, Spatial variation of electric 


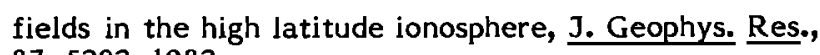
87, 5202, 1982.

M. Blanc and C. Mazaudier, Centre de Recherches sur la Physique de l'Environnement/Centre National d'Etudes des Télécommunications, 38-40 Avenue du General Leclerc, 92131 Issy-Ies-Moulineaux, France.

E. Nielsen, Max-Planck-Institut fur Aeronomie,
Postfact 20, D-3411 Katlenburg-Lindau, Federal Republic of Germany.

Min-Yun $\mathrm{Zi}$, Geophysical Department, Peking University, Peking, People's Republic of China.

(Received February 18, 1983; revised August 16, 1983; accepted September $21,1983$. 